Article

\title{
Process and Energy Analysis of Pelleting Agricultural and Woody Biomass Blends
}

\author{
Noorfidza Yub Harun ${ }^{1, *}$, Ashak Mahmud Parvez ${ }^{2}$ and Muhammad T. Afzal ${ }^{2, *}$ \\ 1 Department of Chemical Engineering, Universiti Teknologi PETRONAS, 31750 Bandar Seri Iskandar, \\ Perak, Malaysia \\ 2 Department of Mechanical Engineering, University of New Brunswick, 15 Dineen Drive, Fredericton, \\ NB E3B 5A3, Canada; ashak.parvez@unb.ca \\ * Correspondence: noorfidza.yub@utp.edu.my (N.Y.H.); mafzal@unb.ca (M.T.A.)
}

Received: 6 March 2018; Accepted: 30 March 2018; Published: 29 May 2018

check for updates

\begin{abstract}
Unprocessed biomass has low energy density and high transportation cost. The energy generated through biomass can be enhanced by the pelletizing technique. In order to evaluate the energy requirement for the pelletizing of agricultural biomass, three different particle sizes (150-300, $300-425$, and 425-600 $\mu \mathrm{m}$ ) of reed canary grass (RCG), timothy hay (TH), and switchgrass (SW) were selected in the present work. Furthermore, two woody biomasses (spruce and pine) were also considered under similar experimental conditions for comparison purposes. An Instron machine attached to an in-house built pelletizer unit was employed to produce a single pellet. The energy demand for compacting ground biomass (spruce) with a particle size of $150 \mu \mathrm{m}$ was lower (2.07 kJ) than those required for particle sizes of $300 \mu \mathrm{m}(2.24 \mathrm{~kJ})$ and $425 \mu \mathrm{m}(2.43 \mathrm{~kJ})$. The energy required for compacting ground reed canary grass, timothy hay, and switchgrass was lower $(1.61,1.97$, and $1.68 \mathrm{~kJ}$, respectively) than that required for spruce $(2.36 \mathrm{~kJ})$ and pine $(2.35 \mathrm{~kJ})$, evaluated at a $159-\mathrm{MPa}$ load and at temperature of about $80^{\circ} \mathrm{C}$. The energy demand for blended biomass was around $2 \mathrm{~kJ}$ with the pellet quality approaching that of the pellets made from woody biomass. Overall, blending helped to improve the quality of pellets and lower the compaction energy requirements.
\end{abstract}

Keywords: biomass pellet; energy of compaction; energy analysis; agricultural biomass; biomass blends

\section{Introduction}

Demand for sustainable alternative energy is growing, caused by energy security and global climate change concerns [1,2]. The share of renewable energy from biomass feedstock resources will be significant in the future energy mix [3-5]. Traditionally, the biomass-based fuel industry has been dependent on forestry biomass. However, biomass from forestry alone is insufficient to meet the future energy targets from biomass. Over the recent years, demand of pellet fuel is increasing due to its high efficiency and environmentally friendly characteristics. Despite the fact that biomass from the agricultural sector has the potential to increase the overall biomass amount, the quality of agricultural biomass-derived pellets is low in terms of physical and chemical properties [6,7]. In general, the collection and preprocessing of biomass have been regarded key factors for efficient, profitable, and sustainable bioenergy production $[3,6,8]$. Low energy density, particularly that of agricultural biomass [9], makes the cost of feedstock logistics high. This cost is about $40-60 \%$ of the total costs of biomass energy production, while the transportation cost alone represents 13 to $28 \%[9,10]$.

Thermodynamic analysis is a useful technique to identify the actual energy required for the pelleting process [10]. This approach has also been used for the energetic assessment of the biomass pelleting process, particularly to assess the energy requirement in biomass compaction process. The design and development of a mechanical compaction and thermal energy requirement for powdery and pharmaceutical products 
have been widely studied in contrast to biomass compaction energy requirements [9]. The different sub-processes of compaction, unloading, and ejection are accounted for in the total energy consumption. The compaction process starts as the ground biomass flow under pressure. Further compression during volume reduction of the material, for instance, for brittle materials, may require additional work $[11,12]$. The compression process also produces significant resistance at the wall of the die and shear stress at the edges of the pellet, which can result in extra consolidation [11,12]. Unloading and decompression may increase the volume of the pellet due to elastic recovery. Afterwards, the ejection in the form of a pellet is the net result of the bond formation of the pelleting. This ejection event imparts a significant stress on the pellet from the unequal distribution of force throughout the pellet. The work and total energy consumption for all of the procedures of compaction can be evaluated using a compaction simulator, which has hydraulic actuators to control a uniform force during the pelleting of biomass.

Biomass possesses a wide range of physical, chemical, and mechanical properties [12,13] which have effects on the thermodynamic and calorimetry analysis of the biomass pelleting process. Harun and Afzal [12] reported that pellet density has a strong dependence on the particle size for both agricultural and woody biomasses, where smaller particles result in a greater energy density. It was also found that blending agricultural biomass with woody biomass improved the compaction bonding as well as the durability of pellets (pellet durability index, PDI $>90 \%$ ) as compared to the pellets made from agricultural biomass alone (PDI $<70 \%$ ) [12]. In the present work, the energy required to pelletize biomass was assessed using a single pelletizer unit attached to an Instron compaction machine. The main objective of this study was to compare the mechanical work and total energy requirement for pelleting various woody and agricultural biomasses, as well as their blends.

\section{Material and Methods}

In this work, the selected agricultural biomass samples such as reed canary grass, switchgrass, and timothy hay were collected from farms near Fredericton, New Brunswick, Canada. Two species of forestry biomass, i.e., spruce and pine, were obtained as woodchips from a sawmill in the Fredericton area. The raw materials stored in plastic container at room temperature. Prior to analysis, the samples were dried in an oven at $105^{\circ} \mathrm{C}$ for $24 \mathrm{~h}$, and then ground using a Wiley mill (Thomas Scientific, Swedesboro, NJ, USA) to less than a 1-mm particle size. Afterwards, pure and blended ground samples were stored in airtight container prior to pelletizing and further analysis. Each test was repeated at least three times to minimize the experimental error.

\subsection{Chemical and Compositional Characterization}

The physical and chemical properties of biomass, which influence its behavior as a fuel, also determine the density, stability, and durability of the pellet. Physical properties of interest include the moisture content, particle size, bulk density, porosity, and thermal properties. Chemical properties of importance include the proximate and ultimate analysis, and the higher heating value (HHV). Apart from the chemical composition of the biomass, the physical properties are the most important parameters for the binding mechanisms of biomass compaction [14].

Each sample was ground in a Wiley mill (Thomas Scientific, Swedesboro, NJ, USA) to pass a 0.300-mm to 0.425-mm screen according to ASTM Standard Practice E 1757-01 [15]. The heating value was measured in a Parr 6200 Isoperibol Oxygen Bomb Calorimeter (a relative standard deviation of $<0.2 \%$ ) according to ASTM standard method D5865 [16], and the ultimate analysis was determined using an elemental analyzer (CHNS 932, LECO Corp., St. Joseph, MI, USA) per ASTM standard method D5291 [17]. The proximate analysis was determined using a thermogravimetric analyzer (TGA Q500, TA Instrument, Inc., New Castle, DE, USA) per ASTM method E1641-04 [18], while ash content was analyzed in a muffle furnace according to NREL/TP510-42622 [12]. The lignin content was determined by means of hydrolysis as per NREL 2008b standard [19]. 


\subsection{Process of Compaction for Biomass Pellets}

Ground biomass was chosen for the pelleting process in order to encompass compaction behavior and simulate all events of the sub-processes of compaction, unloading, and ejection. The magnitude of work was evaluated during the pelleting of spruce, pine, reed canary grass, switchgrass, timothy hay, and their blends. The closed-end die pelletizer attached to an Instron compaction machine with control software was used for the compaction simulation as described previously $[11,13]$. For each test, $1.2 \mathrm{~g}$ of biomass sample was fed into die in each run to produce a single pellet. The close end die with an 8-mm diameter and a 202-mm length was used in the Instron machine, which controlled the load and holding time. The energy required to densify the individual biomass and blended samples pellets was determined using plot of the force and displacement data recorded by the associated software of the Instron machine.

\subsection{Surface Fraction Analysis}

A scanning electron microscopy (SEM) image of each pellet was investigated to see the bonding characteristics between particles that were created through solid bridges. The solid bridges were developed by the diffusion of molecules, crystallization of components, and the chemical reaction or solidification of melted components during the compaction (pelleting) process. The fracture surface analysis is important (mainly due to the bonding mechanism in the pellet) to evaluate the compaction behavior, especially for new pellets made from blended biomasses. The equipment used was a JEOL JSM6400 Digital SEM equipped with Geller dPict digital image acquisition software, Emitech K1250 Cryo-SEM system.

\section{Results and Discussion}

\subsection{Chemical Analysis}

The chemical property of fuel is most important as it influences the method of obtaining the thermal energy and compaction design [14]. During compaction, the heat resulting from friction softens the lignin which binds the ground biomass. It is important to note that lignin is a very important substance in the compaction process because of its adhesive effects on the compressed material. The transformation of biomass into pellets is conducted to increase the energy density. For this reason, the relevant chemical analyses-including proximate and ultimate analyses-are presented in Table 1 . The relative standard deviation for the proximate analysis was $\pm 1.3 \%$, while the value for the ultimate analysis was $\pm 0.19 \%$. It can be seen that the carbon and oxygen contents of individual and blended biomasses were found to be in the range of 45.0 to $47.2 \%$ and 46.6 to $48.8 \mathrm{wt} \%$, respectively (Table 1 ). Moreover, the heating value of RCG, timothy hay (TH), and switchgrass (SW) was lower compared to that of woody biomass due to the higher carbon and hydrogen contents in woody biomass. Lignin content in woody biomass is also in agreement with the calorific value when compared to lignin content in agricultural biomass, since the HHV of lignocellulose biomass is positively correlated with lignin content. Accordingly, the calorific value improved after the blending process.

The Pellet Fuel Institute (PFI) Standard establishes a maximum of 10\% moisture content of pellets [20]. In this study, all of the selected biomasses were analyzed for their moisture content after grinding and being stored in airtight containers for 1 week. As can be seen in Table 1, the moisture content of RCG $(6.4 \%)$, timothy hay $(6.9 \%)$, and switchgrass $(7 \%)$ is lower than that of spruce $(8 \%)$ and pine $(9.3 \%)$. This low moisture content in agricultural biomass may be the reason for the low quality of pellets, as it is too dry for compaction. It is important to mention that the moisture content of the material is one of the crucial factors for the optimal compaction. During pelleting, heat is supplied (which is mainly from frictional heat developed in the die) to form a pellet and therefore, the biomass requires certain amount of moisture to bind the particles so that the pellet is compacted and retains its binding formation [21]. 
Table 1. Fuel and chemical analysis (dry basis) of individual and blended biomass (50:50).

\begin{tabular}{cccccccccccc}
\hline \multirow{2}{*}{ Properties/Components } & \multirow{2}{*}{ RCG } & \multirow{2}{*}{ TH } & \multirow{2}{*}{ SW } & S & $\mathbf{P}$ & $\begin{array}{c}\text { S }+ \\
\text { RCG }\end{array}$ & $\begin{array}{c}\mathbf{P}+ \\
\text { RCG }\end{array}$ & $\begin{array}{c}\text { S }+ \\
\text { TH }\end{array}$ & $\begin{array}{c}\mathbf{P}+ \\
\text { TH }\end{array}$ & $\begin{array}{c}\text { S }+ \\
\text { SW }\end{array}$ & $\begin{array}{c}\mathbf{P}+ \\
\text { SW }\end{array}$ \\
\hline HHV (MJ/kg) & 18.61 & 17.58 & 18.20 & 19.15 & 19.75 & 18.76 & 19.00 & 18.07 & 18.68 & 18.46 & 18.44 \\
HHV (BTU/lb) & 7996 & 7561 & 7825 & 8232 & 8493 & 8065 & 8168 & 7768 & 8031 & 7936 & 7928 \\
C & 45.45 & 45.46 & 45.03 & 47.14 & 46.80 & 46.64 & 45.98 & 46.57 & 46.72 & 47.12 & 47.21 \\
H & 5.89 & 5.95 & 5.98 & 6.06 & 6.14 & 6.06 & 6.02 & 6.01 & 6.08 & 6.08 & 6.12 \\
N & 0.174 & 0.184 & 0.119 & 0.040 & 0.039 & 0.035 & 0.036 & 0.04 & 0.038 & 0.033 & 0.027 \\
S & 0.041 & 0.041 & 0.028 & 0.002 & 0.002 & 0.016 & 0.017 & 0.018 & 0.017 & 0.013 & 0.01 \\
O & 48.44 & 48.37 & 48.84 & 46.76 & 47.02 & 47.13 & 46.97 & 47.36 & 47.14 & 46.75 & 46.64 \\
Lignin & 17 & 11 & 12 & 23 & 24 & 19 & 16 & 13 & 18 & 17 & 14 \\
Ash & 5.34 & 4.06 & 3.61 & trace & trace & 2.07 & 1.54 & 1.51 & 1.62 & 1.53 & 1.55 \\
MC & 6.4 & 6.9 & 7.0 & 8.0 & 9.3 & 7.2 & 7.5 & 7.3 & 7.6 & 7.7 & 7.5 \\
VM & 65 & 66 & 78 & 70 & 70 & 69 & 70 & 70 & 69 & 73 & 71 \\
FC & 23.26 & 23.04 & 11.39 & 22. & 20.70 & 21.73 & 20.96 & 21.19 & 21.78 & 17.77 & 19.95 \\
\hline
\end{tabular}

$\mathrm{HHV}=$ Higher heating value, $\mathrm{RCG}=$ reed canary grass, $\mathrm{TH}=$ timothy hay, $\mathrm{SW}=$ switchgrass, $\mathrm{S}=$ spruce, $\mathrm{P}=$ pine $\mathrm{MC}=$ moisture content, $\mathrm{VM}=$ volatile mater, $\mathrm{FC}=$ fixed carbon $(\mathrm{FC}=100$-ash-VM-MC), trace $(<1 \%)$.

\subsection{Work of Compaction}

The work required to pelletize individual and blended samples was evaluated by means of integrating the area under the compaction curve and relaxation curve, as shown in Figure 1 [22]. The amount of work was determined using the force versus displacement graph. The process a-b-c-d is represented by the compaction curve (a-d), which includes the work required to transfer biomass into the die (a-b), to tamp down the biomass at a lower punch (pre-compaction zone, $b-c)$, and to consolidate the biomass, taking into account the friction (c-d).

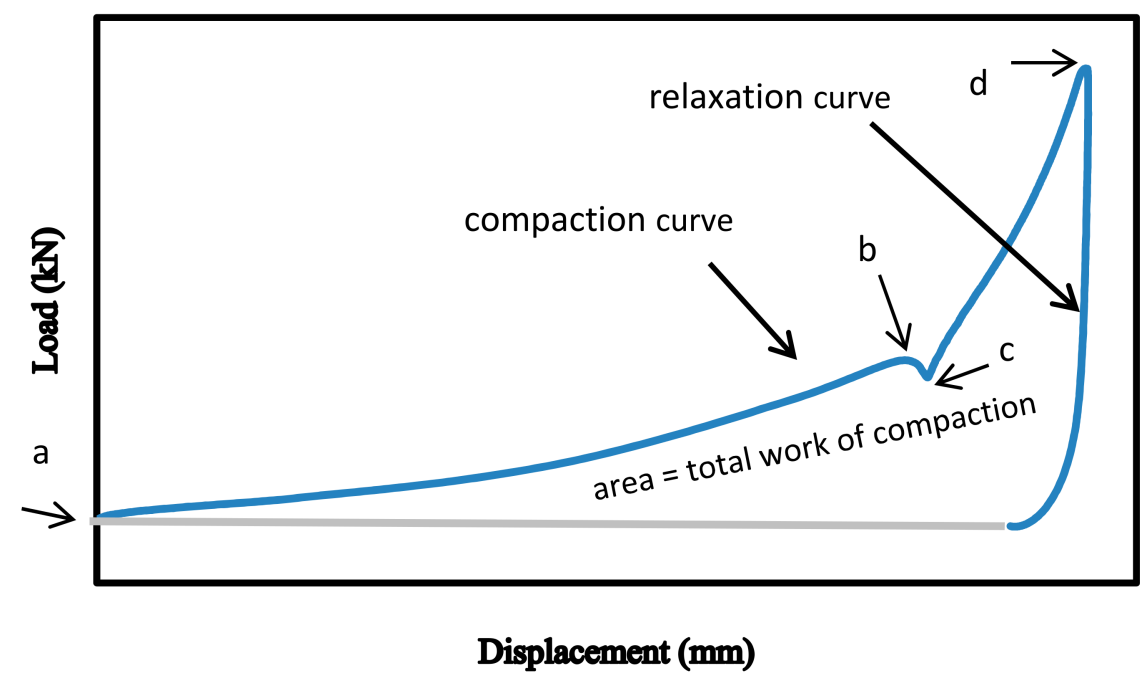

Figure 1. Force-displacement curves during the compaction of biomass pellets.

Figure 2 schematically illustrates the pelletizing process in a cylindrical die channel. It can be seen from Figure 2 that the compaction (pelletizing) process can be separated into component sequences of workflow $\left(\right.$ Work $_{\text {flow }}$ ), pre-compression (Work comp $_{\text {), and work of friction (Work }}$ fric ) of biomass particles. Therefore, the total work of compaction can be obtained as the sum of the individual energy requirements for these components minus the relaxation component (relieved from compaction). 

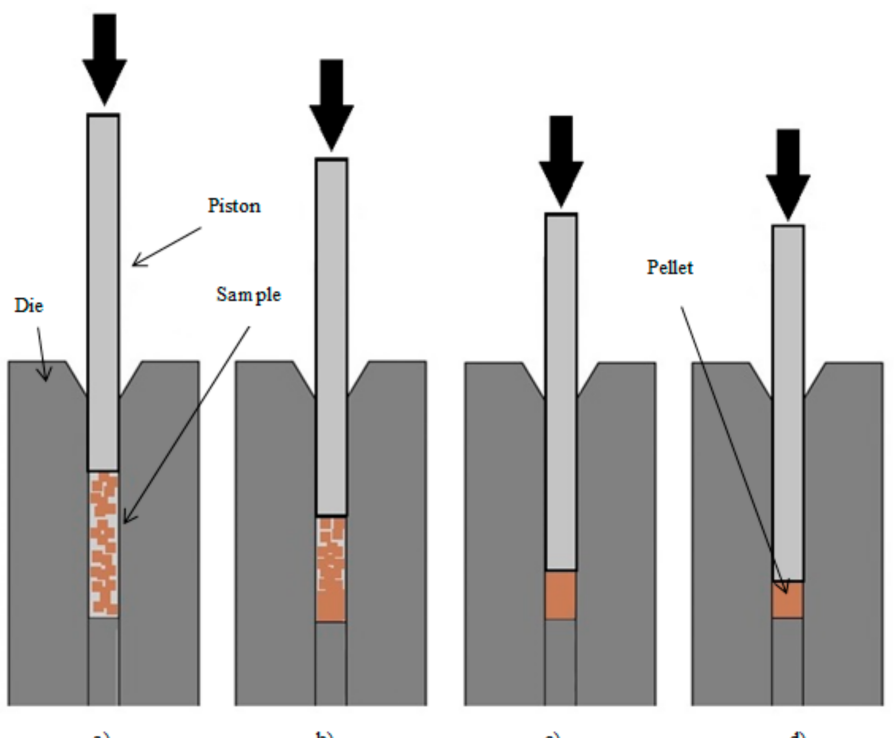

c)

d)

Figure 2. Illustration of compaction processes for energy analysis. Process $(\mathbf{a}, \mathbf{b})$ workflow, Work flow

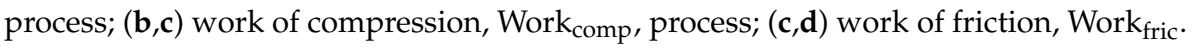

The pressure of $159 \mathrm{MPa}$ and temperature of $80{ }^{\circ} \mathrm{C}$ in the die caused the particles to bond together due to natural adhesion processes $[12,21,23]$. It should be noted that in this study no adhesives were used while pelletizing biomass. The surface-to-surface bonding of the particles may have contributed significantly to the strength of the pellets, and the extent of the bonding largely depended on the lignin and the moisture content of the biomass [24].

Figure 3 illustrates the force vs piston position. This method was used to calculate the energy required in the Work flow $_{\text {, Work }}$ comp, and Work $k_{\text {fric }}$ measurements. For instance, the Work flow $_{\text {was }}$ calculated as the area under the plot in Figure 3a while the biomass was transferred into the die by process a-b in Figure 2. The Work $\mathrm{comp}_{\text {cos }}$ was calculated as the area under the plot in Figure $3 \mathrm{~b}$ while all biomass was tamped down at a lower pressure to allow the air between particles to escape, as presented by the process b-c in Figure 2. This is also indicated by the curve b-c in Figure 1. Finally, the Work $\mathrm{fric}_{\mathrm{c}}$ was calculated as the area under the plot in Figure $3 \mathrm{c}$ while the flattened biomass formed pellets according to the process c-d in Figure 2.

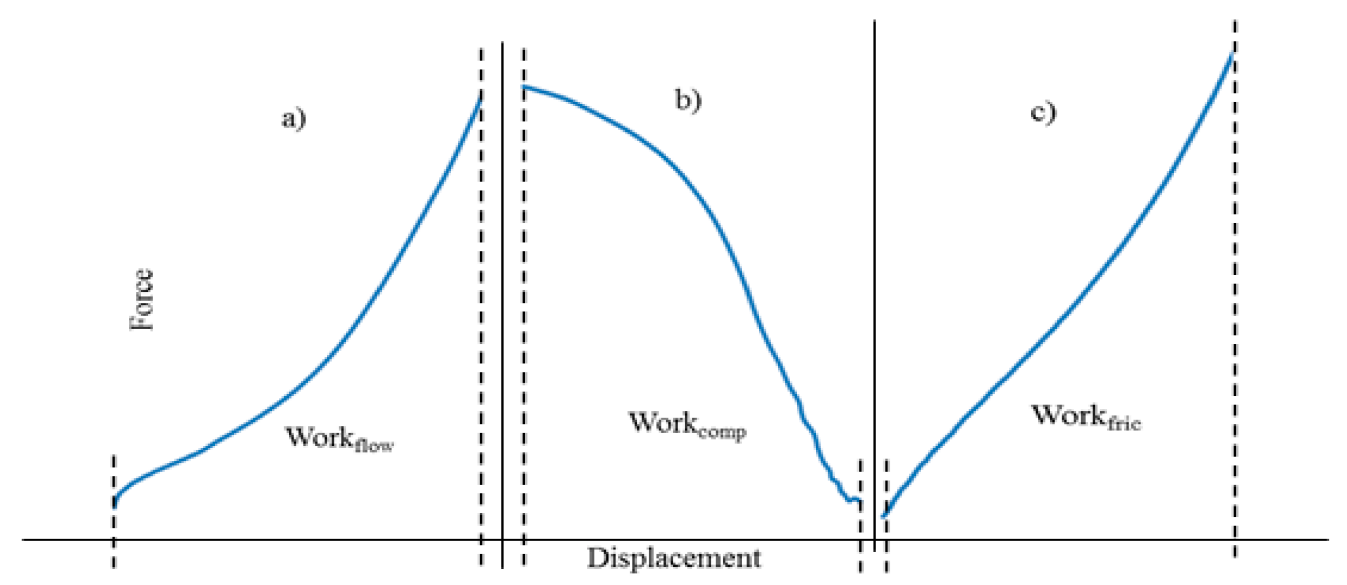

Figure 3. Plot force $(\mathrm{kN})$ displacement $(\mathrm{mm})$ behavior used for Work flow, Work $_{\text {comp, and }}$ Work $_{\text {fric }}$ measurement. 


\subsection{Work Needed to Pelletize Biomass of Different Particles Sizes}

The effect of the work of compaction of materials depends on the particle surface area [25]. The work required to pelletize the woody biomass (spruce) at different particle sizes is illustrated in Figure 4. For spruce, a larger phase area was obtained for making pellets with particle sizes of 150-300 $\mu \mathrm{m}$ as compared to $300-425$ and $425-600 \mu \mathrm{m}$ particle sizes. This indicates that less energy is needed to pelletize spruce with smaller particle sizes. A similar trend was obtained in other individual and blended biomass samples.

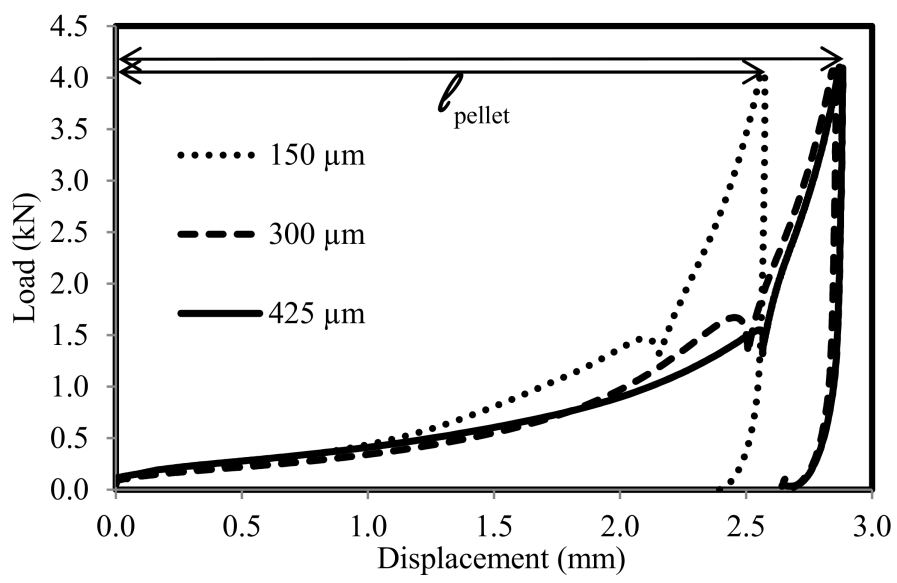

Figure 4. Load-displacement profiles of spruce with particle sizes of $150 \mu \mathrm{m}(\Sigma$ Area $=2.07 \mathrm{~kJ}), 300 \mu \mathrm{m}$ $(\Sigma$ Area $=2.24 \mathrm{~kJ})$, and $425 \mu \mathrm{m}(\Sigma$ Area $=2.43 \mathrm{~kJ})$.

\subsection{Work Needed to Pelletize Biomass and Blended Biomasses (50:50)}

The differences in the flow work, compression work, and friction work components during the pelletizing of forestry or agricultural biomass as well as blended biomasses (shown in Table 2) were primarily due to the differences in their chemical and physical constituents. The high lignin and moisture contents (Table 1) in spruce and pine biomass might be a cause of high flow work since they might increase the viscous nature of the sample. A higher compression force was required to pelletize pine in comparison to other biomasses. This could be related to the presence of chemical extractives in pine [26], which are reported to act as plasticizers. Low friction during the pelletizing of agricultural biomass was observed due to the bonding or interaction mechanism between the pellet surfaces and the die wall. Inter-particle bonding in agricultural biomass is also weaker than the that in forestry biomass, as reported earlier [12,27].

Table 2. Results of workflow, work of compression, and work of friction processes of individual biomass and their blends (50:50) (standard deviation $\pm 1.6 \%$ ).

\begin{tabular}{ccccc}
\hline Sample & $\mathbf{W}_{\text {flow }}(\mathbf{J})$ & $\mathbf{W}_{\text {comp }}(\mathbf{J})$ & $\mathbf{W}_{\text {fric }}(\mathbf{J})$ & $\mathbf{W}_{\text {total }}(\mathbf{J})$ \\
\hline Spruce & 1.23 & 0.14 & 1.06 & 2.36 \\
Pine & 1.23 & 0.27 & 0.92 & 2.35 \\
RCG & 0.94 & 0.17 & 0.57 & 1.61 \\
Hay & 1.18 & 0.18 & 0.68 & 1.97 \\
Switchgrass & 0.98 & 0.05 & 0.72 & 1.68 \\
RCG + spruce & 1.20 & 0.04 & 0.92 & 2.09 \\
RCG + pine & 1.12 & 0.07 & 0.88 & 1.99 \\
Hay + spruce & 1.15 & 0.02 & 0.94 & 2.04 \\
Hay + pine & 1.17 & 0.04 & 1.01 & 2.15 \\
Switchgrass + spruce & 1.02 & 0.13 & 0.75 & 1.83 \\
Switchgrass + pine & 1.11 & 0.06 & 0.81 & 1.91 \\
\hline
\end{tabular}


The total energy required to pelletize individual biomasses and their blends is shown in Table 2 . It is apparent that the mechanical properties of the pellet are highly correlated to the total energy requirement. For instance, forestry biomass provides pellets with better mechanical properties due to the higher work load or energy consumed to pelletize them, as compared to pellets made from agricultural biomass. As the work or energy needed to pelletize the biomass materials increase, there is a greater possibility of enhanced inter-particle bonding between the particles and, consequently, fewer voids in the pellet. Furthermore, the contribution of lignin content from the forestry biomass to the blended pellet might also have increased the work needed to pelletize the biomass material.

\subsection{Fracture Analysis of Forestry and Agricultural Biomass Pellet}

Figure 5 shows SEM images of the microstructure fracture surface of pine, RCG, and timothy hay biomass pellets. From Figure 5a, it was observed that pine showed stronger inter-particle bonding than RCG (Figure $5 b$ ) and timothy hay (Figure $5 c$ ). The high moisture content $(9.3 \%$ ) and high lignin content $(24 \%)$ in pine might be responsible for the strength of the pellet. Biomass with a smaller particle size $(150 \mu \mathrm{m})$ can cause the lignin to squeeze out due to pressure, temperature, and compaction during the pelleting process. Smaller particles can encourage the particles to bind and compact, as this requires a lower amount of work (Figure 4) to yield quality pellets as compared to larger particles. The particle bonding in RCG (Figure $5 b$ ) is most likely due to the combination of particle entanglement and auto-adhesive surfaces [26,28].

Timothy hay and switchgrass revealed poor particle-to-particle bonding since no adhesive surface was found at any site of fracture surface of the pellet. The images showed only the entanglement of particles in pellets made from timothy hay and switchgrass. This might provide evidence that the lignin content in the biomass is responsible for the mechanical properties of the pellet [28]. Pressure, temperature, and moisture promote adhesion by bonding with a solid bridge between particles. Based on the adhesion theories, when the maximum attractive force reaches the minimum potential energy, chemical bonding is established. Materials in ground form also contribute to the particle bonding. The effectiveness of these forces diminishes dramatically as the size of the particles or inter-particle distance increases $[25,29]$.

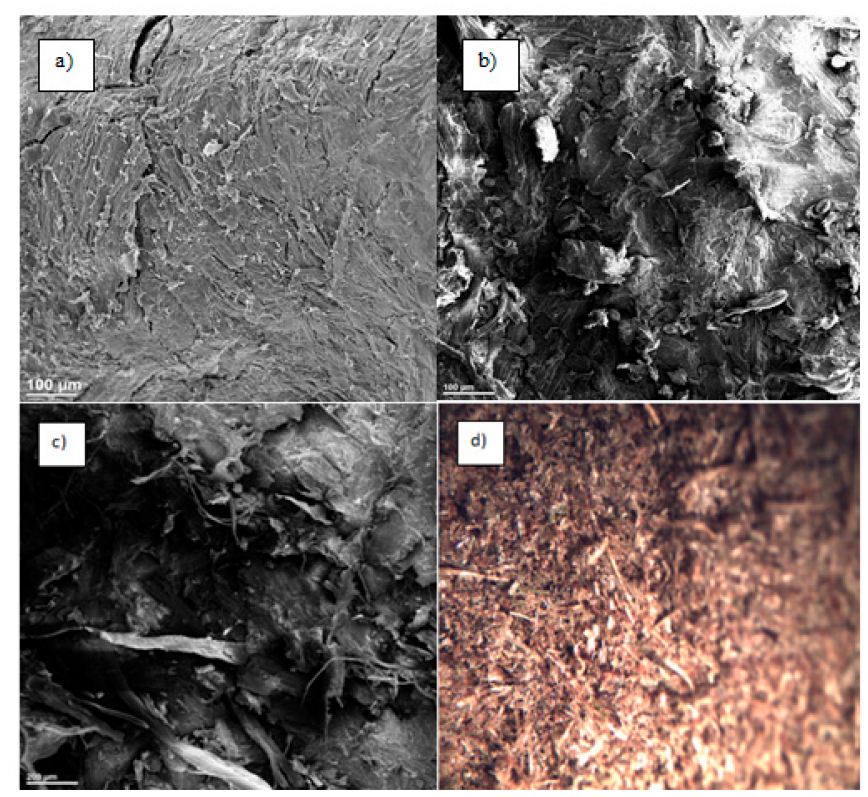

Figure 5. SEM images of fracture surfaces for pellets with a particle size of $150 \mu \mathrm{m}$ of: (a) pine (at magnification $100 \mu \mathrm{m}$ ), (b) RCG (at magnification $100 \mu \mathrm{m}$ ), (c) timothy hay (at magnification $200 \mu \mathrm{m}$ ), and (d) timothy hay (optical image). 


\section{Conclusions}

The effect of blending agricultural biomass with woody biomass on the mechanical work of compaction was investigated in the current study. It was found that blending agricultural biomass with woody biomass not only resulted in better quality pellets, but also resulted in a lower energy requirement for compaction as compared to pelleting woody biomass alone. Thus, the blending of selected biomasses can significantly reduce the energy requirement and the overall cost of the pellet production process.

Author Contributions: N.Y.H. and M.T.A. conceived and designed the experiments; N.Y.H. performed the experiments and analyzed the data; M.T.A. contributed reagents/materials/analysis tools; N.Y.H. wrote the paper; A.M.P. and M.T.A. reviewed and proof read the paper.

Acknowledgments: The authors appreciate the financial assistance from New Brunswick Department of Agriculture, Aquaculture, and Fisheries; New Brunswick Soil and Crop Improvement Association; New Brunswick Agricultural Council; Agriculture and Agri-Food Canada; New Brunswick Innovation Foundation; and Universiti Teknologi PETRONAS, Malaysia.

Conflicts of Interest: The authors declare no conflict of interest.

\section{References}

1. Gan, J.; Smith, C.T. A Comparative Analysis of Woody Biomass and Coal for Electricity Generation Under various $\mathrm{CO}^{2}$ Emission Reductions and Taxes. Biomass Bioenergy 2006, 30, 296-303. [CrossRef]

2. Chu, S.; Cui, Y.; Liu, N. The Path Towards Sustainable Energy. Nat. Mater. 2017, 16, 16-22. [CrossRef] [PubMed]

3. Miao, Z.; Shastri, Y.; Grift, T.E. Lignocellulosic Biomass Feedstock Transportation Alternatives, Logistics, Equipment Configurations, and Modeling. Biofuels Bioprod. Biorefin. 2012, 6, 351-362. [CrossRef]

4. Somerville, C.; Youngs, H.; Taylor, C. Feedstocks for Lignocellulosic Biofuels. Science 2010, 329, 790-792. [CrossRef] [PubMed]

5. Ayer, N.W.; Dias, G. Supplying Renewable Energy for Canadian Cement Production: Life Cycle Assessment of Bioenergy from Forest Harvest Residues using Mobile Fast Pyrolysis Units. J. Clean. Prod. 2018, 175, 237-250. [CrossRef]

6. Zamorano, M.; Popov, V.; Rodríguez, M.L. A Comparative Study of Quality Properties of Pelletized Agricultural and Forestry Lopping Residues. Renew. Energy 2011, 36, 3133-3140. [CrossRef]

7. Blake, C.D.; Street, J.T.; Wooten, J. Additives in biomass pellets for improvements in physical properties. In Proceedings of the 2017 ASABE Annual International Meeting, Anonymous American Society of Agricultural and Biological Engineers, Washington, DC, USA, 16-19 July 2017; p. 1.

8. Buytaert, V.; Muys, B.; Devriendt, N. Towards Integrated Sustainability Assessment for Energetic use of Biomass: A State of the Art Evaluation of Assessment Tools. Renew. Sustain. Energy Rev. 2011, 15, 3918-3933. [CrossRef]

9. DeCrosta, M.T.; Schwartz, J.B.; Wigent, R.J. Thermodynamic Analysis of Compact Formation; Compaction, Unloading, and Ejection: II. Mechanical Energy (Work) and Thermal Energy (Heat) Determinations of Compact Unloading and Ejection. Int. J. Pharm. 2001, 213, 45-62. [CrossRef]

10. Adapa, P.K.; Tabil, L.G.; Schoenau, G.J. Factors Affecting the Quality of Biomass Pellet for Biofuel and Energy Analysis of Pelleting Process. Int. J. Agric. Biol. Eng. 2013, 6, 1-12.

11. Rowlings, C.E.; Wurster, D.E.; Ramsey, P.J. Calorimetric Analysis of Powder Compression: II. the Relationship between Energy Terms Measured with a Compression Calorimeter and Tableting Behavior. Int. J. Pharm. 1995, 116, 191-200. [CrossRef]

12. Harun, N.Y.; Afzal, M.T. Chemical and Mechanical Properties of Pellets made from Agricultural and Woody Biomass Blends. Trans. ASABE 2015, 58, 921-930.

13. Jönsson, L.J.; Martín, C. Pretreatment of Lignocellulose: Formation of Inhibitory by-Products and Strategies for Minimizing their Effects. Bioresource Technol. 2016, 199, 103-112. [CrossRef] [PubMed]

14. Whittaker, C.; Shield, I. Factors Affecting Wood, Energy Grass and Straw Pellet Durability-A Review. Renew. Sustain. Energy Rev. 2017, 71, 1-11. [CrossRef] 
15. Tortosa Masiá, A.A.; Buhre, B.J.P.; Gupta, R.P. Characterising Ash of Biomass and Waste. Fuel Process. Technol. 2007, 88, 1071-1081. [CrossRef]

16. Tangsathit, S.; Sanongraj, S. Technique for Production of Paperboard Briquette from Wastepaper. Suranaree J. Sci. Technol. 2012, 19, 79-92.

17. Nadkarni, R.; Nadkarni, R. Guide to ASTM Test Methods for the Analysis of Petroleum Products and Lubricants; ASTM International West Conshohocken: Conshohocken, PA, USA, 2007.

18. Das, O.; Sarmah, A.K. Mechanism of Waste Biomass Pyrolysis: Effect of Physical and Chemical Pre-Treatments. Sci. Total Environ. 2015, 537, 323-334. [CrossRef] [PubMed]

19. Sluiter, A.; Hames, B.; Ruiz, R. Determination of Structural Carbohydrates and Lignin in Biomass. Lab. Anal. Proced. 2008, 1617, 1-16.

20. Tumuluru, J.S.; Wright, C.T.; Hess, J.R. A Review of Biomass Densification Systems to Develop Uniform Feedstock Commodities for Bioenergy Application. Biofuels Bioprod. Biorefin. 2011, 5, 683-707. [CrossRef]

21. Križan, P.; Matú, M.; Šooš, L'. Behavior of Beech Sawdust during Densification into a Solid Biofuel. Energies 2015, 8, 6382-6398. [CrossRef]

22. Adapa, P.; Tabil, L.; Schoenau, G. Compaction Characteristics of Barley, Canola, Oat and Wheat Straw. Biosyst. Eng. 2009, 104, 335-344. [CrossRef]

23. Dhamodaran, A.; Afzal, M. Compression and Springback Properties of Hardwood and Softwood Pellets. BioResour. 2012, 7, 4362-4376.

24. Stelte, W.; Holm, J.K.; Sanadi, A.R. A Study of Bonding and Failure Mechanisms in Fuel Pellets from Different Biomass Resources. Biomass Bioenergy 2011, 35, 910-918. [CrossRef]

25. Matsunaga, M.; Obataya, E.; Minato, K. Working Mechanism of Adsorbed Water on the Vibrational Properties of Wood Impregnated with Extractives of Pernambuco (Guilandina echinata Spreng.). J. Wood Sci. 2000, 46, 122. [CrossRef]

26. Gardner, D.J. Adhesion Mechanisms of Durable Wood Adhesive Bonds. In Characterization of the Cellulosic Cell Wall; John Wiley \& Sons, Inc.: Hoboken, NJ, USA, 2006; pp. 254-265.

27. Harun, N.Y.; Afzal, M.T. Effect of Particle Size on Mechanical Properties of Pellets made from Biomass Blends. Procedia Eng. 2016, 148, 93-99. [CrossRef]

28. Mani, S.; Sokhansanj, S.; Bi, X. Economics of Producing Fuel Pellets from Biomass. Appl. Eng. Agric. 2006, 22, 421-426. [CrossRef]

29. Bos, C.E.; Vromans, H.; Lerk, C.F. Lubricant Sensitivity in Relation to Bulk Density for Granulations Based on Starch or Cellulose. Int. J. Pharm. 1991, 67, 39-49. [CrossRef] 